\title{
Réflexions critiques sur l'“Antigone” de J. Anouilh
}

\section{André Georges}

\section{(2) OpenEdition}

\section{Journals}

Édition électronique

URL : https://journals.openedition.org/studifrancesi/4549

DOI : 10.4000/studifrancesi.4549

ISSN : 2427-5856

\section{Éditeur}

Rosenberg \& Sellier

\section{Édition imprimée}

Date de publication : 1 avril 2012

Pagination : 110-112

ISSN : 0039-2944

\section{Référence électronique}

André Georges, «Réflexions critiques sur I'Antigone" de J. Anouilh», Studi Francesi [En ligne], 166 (I |

LVI) | 2012, mis en ligne le 30 novembre 2015, consulté le 18 novembre 2021. URL : http://

journals.openedition.org/studifrancesi/4549; DOI : https://doi.org/10.4000/studifrancesi.4549

\section{(c) (i) ()}

Studi Francesi è distribuita con Licenza Creative Commons Attribuzione - Non commerciale - Non opere derivate 4.0 Internazionale. 


\section{Réflexions critiques sur l'“Antigone" de J. Anouilh}

L'Antigone d'Anouilh est une tragédie classique ou peu s'en faut et le protagoniste un personnage tragique ${ }^{2}$. Est-ce le chef-d'œuvre d'Anouilh, comme on a souvent tendance de le croire? Il faut reconnaître que la pièce n'est pas sans présenter de sérieux défauts tant sur le plan de l'action que sur celui de la dramaturgie. C'est ce que nous voulons montrer ici. Mais auparavant rappelons brièvement la légende qui a inspiré a la fois l'Antigone de Sophocle et l'Antigone d'Anouilh, d'autres Antigone aussi.

CEdipe, fils de Laïos et de Jocaste, roi et reine de Thèbes, tue sans le reconnaître son père au carrefour de Pothiai, comme un oracle l'avait prédit. Devenu roi de Thèbes, il épouse Jocaste sans savoir qu'elle était sa mère. De cette union contre nature naissent quatre enfants: Ismène, Antigone, Etéocle et Polynice. Quand CEdipe connaît son malheur, il s'aveugle, et guidé par sa plus jeune fille, Antigone, il se retire à Colone, en Attique, où il bénéficie de la protection de Thésée. Jocaste s'est pendue. Etéocle et Polynice, restés à Thèbes, s'entendent pour régner un an a tour de rôle. Etéocle occupe le premier le trône, mais le moment venu, refuse de le céder a Polynice. Celui-ci gagne Argos, où il réunit une armée avec laquelle il attaque Thèbes. Au cours du combat, les deux frères s'entretuent. L'armée argyenne est défaite, et Créon, frère de Jocaste, prend le pouvoir. Il ordonne pour Etéocle des funérailles solennelles, mais exige, par un décret répandu dans Thèbes, que le cadavre de Polynice soit privé de sépulture. Une telle décision condamnait le défunt à errer éternellement au lieu de trouver le repos dans l'Au-delà.

C'est à ce point de cette légende que commence la pièce d'Anouilh. Créon règne sur Thèbes avec Eurydice, qui n'apparaît que dans l'exposé du Prologue. Vivent également dans le palais royal les deux filles d'Edipe et de Jocaste, Ismène et Antigone, qui sont les nièces de Créon. Ismène, l'aînée, est très belle, elle est blonde, toujours élégamment vêtue, elle aime la danse et les divertissements mondains. Antigone, tout au contraire, est maigre, petite, noiraude, renfermée et n'attache aucune importance a ses toilettes. Elle est fiancée à Hémon, fils de Créon et d'Eurydice. C'est le protagoniste, le personnage central autour duquel s'organise l'action. La décision de Créon de n'accorder aucune sépulture à Polynice oppose les deux sœurs. A trois reprises, Ismène intervient: deux fois pour détourner Antigone de violer le décret de Créon, la troisième fois pour prendre son parti face à leur oncle, au cas où celui-ci condamnerait à mort Antigone. Ismène joue donc dans l'action un rôle non négligeable. Pourtant, après sa dernière intervention, elle disparaît, et, au dénouement, les spectateurs resteront dans l'ignorance de son sort. Ceci est formellement contraire à

(1) Je me réfère â l'édition d'Antigone de J. Anouilh, publiée par la Table Ronde en 1946.

(2) Voir mon article L'Antigone de Jean Anouilh.
Dramaturgie et psychologie, dans «Revue d'Histoire du Théâtre», 2002, 4, pp. 347-358. 
la dramaturgie classique qu'Anouilh respecte pour l'essentiel'3. Selon, en effet, cette dramaturgie, le dénouement d'une tragédie doit être complet. Il existe deux façons pour qu'il le soit. Normalement, le public doit être fixé sur le sort de tous les personnages principaux et connaître la solution de tous les problèmes qui se sont posés dans le nœud. Mais dans certains cas, une partie du dénouement peut être simplement suggérée, comme dans Le Cid et Polyeucte, de Corneille ou encore dans Andromaque de Racine. Or il est évident que ni d'après la première, ni d'après la seconde façons, le dénouement d'Antigone n'est complet. On connaît le sort d'Antigone, d'Hémon, d'Eurydice, de Créon, on ignore totalement le sort d'Ismène. Sans doute, lors de sa troisième intervention, a-t-elle déclaré qu'elle aussi irait le lendemain, recouvrir le corps de Polynice. Mais le dénouement est antérieur au «lendemain» et c'est quand la pièce se dénoue que le sort de tous les personnages doit être connu, au moins pour l'essentiel. Ira-t-elle d'ailleurs le lendemain inhumer son frère et, si elle y va, sera-t-elle, comme Antigone, mise a mort? On ne le saura jamais. Peut-être, certains objecteront-ils que l'auteur n'était pas obligé de respecter sur ce point la doctrine classique. Mais doctrine classique ou non, le dénouement d'une pièce de théâtre doit être complet ou les spectateurs restent insatisfaits. Et ils le seront d'autant plus ici que les dernières paroles du chœur, avant que ne se ferment les rideaux, soulignent la solitude de Créon dans le palais vide, ce qui contredit la réalité, puisqu'Ismène est vivante, et cela ne devrait pas manquer de choquer.

On est ainsi amené à reconnaître que, sur le plan dramaturgique, la tragédie d'Anouilh, comme du reste celle de Sophocle, laisse à désirer. Mais il y a plus grave, et cette fois ce qu'il nous faut envisager c'est l'action proprement dite. D'après la légende, Etéocle et Polynice étaient des princes vertueux - du moins rien n'est dit en sens contraire. En revanche dans la pièce d'Anouilh, Polynice est un vaurien, un révolté, un voyou. Après une dispute avec son père, il quitta Thèbes et s'engagea dans l'armée argyenne. Mais Etéocle ne valait pas mieux. Comme son frère, il avait voulu faire assassiner son père. Voici d'ailleurs ce qu'à cet égard Créon révèle à Antigone: «Etéocle, ce prix de vertu, ne valait pas plus cher que Polynice. Le bon fils avait essayé, lui aussi, de faire assassiner son père [...]. Cette trahison pour laquelle le corps de Polynice est en train de pourrir au soleil, j'ai la preuve maintenant qu'Etéocle [...] se préparait, lui aussi, à la commettre. C'est un hasard si Polynice a réussi son coup avant lui». Si on comprend bien ce texte qui n'est pas des plus clairs, Etéocle se preparait («avait essayé», «se préparait») à faire assassiner son père quand il fut devancé par Polynice. Il s'ensuit que, contrairement a la légende thébaine, Edipe régnait encore à Thèbes quand ses deux fils s'affrontèrent «pour vendre Thèbes au plus offrant». Il périt, frappé par un tueur a la solde de Polynice, avant que les deux princes ne s'entretuent dans le combat qui oppose les Thébains aux Argyens. Une telle version des faits contredit la légende sur des points essentiels: la prise de conscience d'CEdipe après qu'un oracle eut révélé que la peste qui sévissait a Thèbes ne cesserait qu'avec le châtiment de l'assassin de Laïos; la cécité d'CEdipe due au fait qu'il s'est crevé les yeux; le suicide de Jocaste; le départ d'CEdipe pour Colone sous la conduite d'Antigone; l'alternance sur le trône de Thèbes d'Etéocle et de Polynice. Une telle trahison de la légende est inadmissible. Les faits qu'on vient d'énumérer sont trop connus pour n'être pas respectés. Certains, au demeurant, sont mentionnés par le Prologue 4 , par Antigone $e^{5}$ et par Créon dans son dialogue avec Antigone. («Et le plus simple après c'est encore de se crever les yeux...») ${ }^{6}$, si bien que Créon non seulement

(3) Voir l'article précédemment cité.

(4) Ibidem, p. 13.
(5) Ibidem, p. 18.

(6) Ibidem, p. 69. 
contredit la légende, mais encore se contredit. Antigone, qui connaît parfaitement les faits tels qu'ils se sont passés d'après la légende, ajoute cependant foi aux dires de Créon. L'action est donc ici complètement faussée.

Elle l'est encore ailleurs pour d'autres raisons. Nous visons la scène qui précède le dénouement entre Antigone et un garde. Dans la tragédie de Sophocle, le peuple de Thèbes prend fait et cause pour Antigone. Il approuve son action qui est conforme aux lois non écrites voulues par les Dieux. Dans la tragédie d'Anouilh, c'est l'inverse qui se produit contre toute vraisemblance. Il réagit violemment en apprenant qu'une fille d'CEdipe a enfreint le décret de Créon qui est dépourvu de sens dans le cadre de la pièce, malgré les raisons qu'en donne le roi ${ }^{7}$. Il envahit le palais royal, empêchant les gardes qui emmènent Antigone sur l'ordre du roi, de sortir; ils sont refoulés avec Antigone sur le théâtre. Il en résulte que l'action, au lieu d'évoluer normalement vers son dénouement, est suspendue et qu'on assiste a une nouvelle scène où figure Antigone. Sans doute y avait-il un vide a combler après la scène entre Créon et Hémon, suivie d'une brève intervention du chœur, et avant l'arrivée du messager qui vient annoncer à la reine le suicide d'Antigone et d'Hémon. Mais il ne pouvait absolument pas, l'être par une scène où figurât Antigone, puisque le messager doit annoncer sa mort. Si bien qu'au lieu de résoudre le problème - au reste insoluble - l'auteur se borne à le reporter. Et de fait. À peine Antigone est-elle définitivement sortie du palais, que survient le messager, qui révèle des événements qui ne peuvent s'être produits avant le moment où il les révèle. L'entrée de Créon avec son page, dès que le messager fut sorti, survient également beaucoup trop tôt. De là des invraisemblances inadmissibles qu'il est bien étonnant qu'elles puissent passer inaperçues, même lors des représentations.

D'autres invraisemblances, moins apparentes, sont à noter. Il est invraisemblable qu'Antigone ait été enfermée dans un «trou» ${ }^{8}$, et non, comme le veut la légende, dans une caverne de l'Hadès, aux portes de la ville; qu'elle se soit pendue (a quoi)? avec les (le texte dit «aux») fils de sa ceinture; qu'Hémon ait pu pénétrer dans le tombeau sans que Créon et les gardes s'en soient aperçus. Il est au surplus regrettable qu'Eurydice, à laquelle le messager a été envoyé, ne paraisse pas sur la scène, comme c'est le cas dans la tragédie grecque. Enfin, dans le nœud, la scène où Antigone est prisonnière des gardes est trop longue, elle ralentit inutilement l'action, et la vulgarité des propos tenus par la soldatesque nuit gravement a ce que la doctrine classique appelle l'unité de ton.

Les critiques que nous venons d'exposer sur l'Antigone de J. Anouilh n'autorisent certes pas à penser que c'est une œuvre réussie a tous égards. Faut-il pour autant la condamner? Il est certain que la pièce, malgré tous ses défauts, comporte de grandes qualités. Les personnages d'Antigone, d'Ismène et d'Hémon, du point de vue strictement psychologique, ont beaucoup de vérité et sont donc de nature à nous intéresser et à nous émouvoir, d'autant qu'ils interprètent de façon originale une légende célèbre. C'est ce qui explique que pas mal de scènes sont réussies: celles où interviennent la nourrice, Hémon, Ismène. Il reste que les personnages de Créon et d'Antigone manquent d'authenticité sur le plan de l'action et que leur personnalité est par là même faussée. Enfin il faut reconnaître qu'en situant l'action à une époque indéterminée, qui peut être tantôt la Grèce antique et tantôt la France d'aujourd'hui, l'auteur pêche fatalement contre la vraisemblance. Bref, en dépit de tout ce qu'on peut dire en faveur de la pièce, celle-ci, en définitive, doit être regardée comme une œuvre manquée, et cela est bien surprenant quand on sait les talents de dramaturge de l'auteur.

ANDRÉ GEORGES

(7) Ibidem, pp. 90-91.

(8) Ibidem, p. 118

(9) Ibidem, pp. 59-61. 